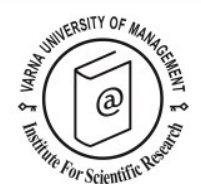

\title{
'To Spray or Not to Spray': Developing a Tourism-Linked Research Agenda for Aircraft Disinsection
}

\author{
Andrea Grout ${ }^{1 *}$
}

Received: 07/08/2014 Accepted: 25/09/2014

\footnotetext{
${ }^{1}$ Independent Public Health Expert, Bergheimerstr.70, 69115 Heidelberg, Germany, Phone: +491737008263 , Fax:+49 6221 7258149, Email: groutandrea@gmail.com

* Corresponding author
}

\begin{abstract}
Increases in international air transport are playing a major role in the global dispersion of mosquitoborne diseases, notably malaria and dengue fever. Disinsection of aircraft is the formal name of the process undertaken to control disease vectors that may be inadvertently imported from endemic regions. The goals of not exposing passengers and crews to insecticides, while also eliminating mosquitoes on flights, are potentially incompatible concerns. Understanding this problematic tourism-health link is important as organisations and individuals strive to make global tourism more sustainable. Aircraft disinsection as a means of disease vector control offers multiple opportunities for tourism research. This review offers a broad study agenda involving tourism and social science work which reaches beyond the medical research paradigm that dominates disinsection studies. It can be suggested that the key question is not whether to side with disinsection or not, but under what conditions is it most effective? Such decisions can be assisted through more integrated aviation and tourism policy analysis, crew and passenger health studies, analysis of crew behaviours and interpretation research.
\end{abstract}

(C) 2015 Varna University of Management. All rights reserved

Keywords: Air travel, vector control, malaria, dengue fever, disinsection, public health

Citation: Grout, A. (2015) 'To Spray or Not to Spray': developing a tourism-linked research agenda for aircraft disinsection. European Journal of Tourism Research 10, pp. 35-50

\section{Introduction}

The health of communities everywhere is affected by contemporary air travel. Understanding the forces at work in shaping the safe transport of people around the globe and limiting the spread of disease are major issues for the future of travel and tourism but have not always been a part of the research agenda of tourism studies (Page, 2009). These concerns motivate and frame the purpose of this analysis which is to provide a tourismlinked research agenda for the better understanding of disease and health management in the airline and wider tourism sector.

The World Health Organization (WHO) defines disinsection as the procedure whereby health 
'To spray or not to spray': developing a tourism-linked research agenda for aircraft disinsection.

measures are taken to control or kill the insect vectors of human diseases present in baggage, cargo, containers, conveyances, goods and postal parcels' (WHO 2004). Mosquitoes can carry some of the world's most serious diseases. The speed and global reach of air travel have together become effective means of increasing the transmission of disease-carrying mosquito vectors and vector-borne diseases across international borders (Gubler 2008). While many vector-borne diseases have been historically confined to distinct geographical areas, increased rates of vector transmission have been linked to the continued expansion of the global air transport network, the effects of climate change, and changes in human movement patterns (WHO, 2003; Lines, 2007).

In a recent and substantial review of transport and tourism Page and Connell (2014) describe the relationship between transport, recreation and tourism studies as requiring much more attention. More positively, they report that concerns about sustainability have fostered a new interest in tourism and transport studies. The dominant issue of sustainability can be seen as including travellers' health concerns and anxieties about their well-being (Mclntosh et al., 1998; Page, 2009). The present interest in disinsection fits within this concern about travellers' ongoing concerns with their safety and all matters affecting their health, whether that be food safety, vaccinations or their likely exposure to contagious diseases. The contemporary concerns tourists have about their health can be linked with much older emphases in tourism studies including the work on tourist motivation which identified the role of stress and anxiety about air travel as a key factor in shaping destination choice (Plog, 1974, 1987). Similarly the motivational frameworks offered by Crompton (1979), IsoAhola (1982), Krippendorf (1987) and Pearce (1988) were built on an understanding that tourists' had confidence in the safety and security of all aspects of their holiday experience. These motivational influences shape destination choice and the traditional set theory approaches describing how tourists decide where they go do build considerations about anxiety and destination safety into the models (Crompton \& Ankomah, 1993). More recently, there has been an emphasis on the use of heuristics as the way individuals make choices (Kahneman, 2012). In the decision context of interest, simple heuristics may be identified as follows: an unwillingness to fly with an airline known to use stress-inducing disinsection procedures. The important implication here is that a concern with disinsection procedures may be enough to shape future travel and while the empirical evidence for this assertion awaits further specific studies, it is conceptually and logically possible to suggest that for a subset of travellers these anxieties are very influential in modifying their travel choices. It can be noted that these health related concerns may be especially powerful in terms of affecting world tourism growth which in many places is dependent on further predicted growth from Asia, especially China. While the issue of tourists' health is of global concern, health and safety topics are well established as dominant issues affecting travel choices for those emanating from China (Kim, Guo \& Agrusa, 2005; Lai, Xi \& Harrill, 2013).

The purpose of this study is to review multiple levels of work concerning aircraft disinsection with the goal of identifying a tourism-studies linked research agenda on fundamental topics. There is an urgent need to establish the effectiveness of disinsection and to gain better understanding of aircrew behavioural patterns towards control procedures. To capture the multidimensional nature of the problem and promote discussion for urgent action, attention is initially directed to the historical development of aircraft vector-control, and attempts to provide a regulatory response. From this account it is argued that the lack of scientific data urges an uptake of collaborative study among tourism researchers, medical professionals, vector biologists, airport managers, and environmental scientists. Ultimately, the roadmap for the control of disease vectors in aircraft will require a novel research-led approach that bridges public health policy, management by tourism interests, and environmental control bodies.

\section{Background}

Major diseases transmitted by Aedes and Anopheles species 
The dominant diseases of concern, amongst several potent and virulent companions, are malaria and dengue fever. Malaria is a lifethreatening disease, common in many tropical and subtropical regions. The WHO reports that malaria currently occurs in 97 countries, some of which are visited by more than 125 million international travellers annually (WHO, 2012a). Among the populations most at risk are nonimmune travellers moving into endemic areas (WHO, 2014). Effective surveillance systems and rigorous control programmes have contributed to a substantial decrease in malaria cases. However, resistance to insecticides used in aircraft disinsection has now been reported in 27 countries in sub-Saharan Africa (WHO, 2005).

Dengue fever is now endemic in over 100 countries and is the most rapidly spreading vector-borne disease in the world (WHO, 2012b). Through increasing population movement, infectious individuals may spread different dengue strains in waves in all directions resulting in co-circulation of virus strains, and facilitating the emergence of dengue haemorrhagic fever (Cummings et al., 2004). While dengue fever generally causes a flu-like illness, dengue haemorrhagic fever is a more severe form of the disease which can result in internal bleeding and potentially death.

A consequence of transporting mosquitoes by aircraft has been 'airport malaria' (for definition, see Table 1), each case representing an importation of infected Anopheles mosquitoes. It was found that anopheline mosquitoes have been imported into France at an estimated rate of 8-20 per flight (Giacomini et al., 1994). Isaäcson (1989) reviewed 29 cases of 'airport malaria', noting that the relatively large number of cases in France reflects the high frequency of flights arriving from Central and West Africa. Cases of 'runway malaria' (Table 1) occurred in Nigeria (Conlon et al., 1990), Gambia and Cote'd Ivoire (Gratz et al., 2000), and a case of 'baggage malaria' (Table 1) was reported by Rizzo et al. (1989).

The other readily transferable diseases with the power to disrupt community life and cause life threatening illness include chikungunya and yellow fever. For the purposes of this review the commonality of the transmission through mosquitoes is the unifying thread influencing the spread of these powerful and highly undesirable diseases.

\section{Mosquito vectors and the burden of disease}

Air transportation is a potent force in mosquito vector invasion. Given the accelerating expansion of global air travel for business and tourism between scattered regions of the world with similar climates, vector-borne disease outbreaks are likely to become increasingly common (Tatem et al., 2006). It is estimated that vector-borne diseases account for $17 \%$ of the global burden of all infectious diseases. Whilst the global response to malaria has greatly reduced rates of morbidity over the past decade, the emergence of resistance to frontline malaria drugs (such as artemisinin) in Cambodia, Myanmar and Thailand could eventually render them obsolete, putting

Table 1. Disease transmission of infected mosquitoes through aircraft

\begin{tabular}{ll}
\hline Airport malaria* $^{*}$ & $\begin{array}{l}\text { Transmission occurs through import of infected } \\
\text { anopheles mosquitoes, able to survive long enough at a } \\
\text { destination to continue malaria transmission. }\end{array}$ \\
Airplane malaria & $\begin{array}{l}\text { Transmission occurs in-flight between malaria-free areas } \\
\text { if an aircraft carries mosquitoes from a previous } \\
\text { operation in malaria endemic areas. }\end{array}$ \\
Runway malaria & $\begin{array}{l}\text { Transmission occurs on flights between malaria-free } \\
\text { areas during a transit stop in endemic areas }\end{array}$ \\
Baggage malaria & $\begin{array}{l}\text { Transmission occurs in malaria-free areas after infected } \\
\text { mosquitoes escape from baggage of travellers from } \\
\text { endemic countries }\end{array}$
\end{tabular}

${ }^{*} A$ subclass of autochthonous malaria (WHO, 1963) 
'To spray or not to spray': developing a tourism-linked research agenda for aircraft disinsection.

Table 2. Disinsection practices approved by the WHO

\begin{tabular}{ll} 
Method of application & Requirements of application \\
\hline Blocks-away & $\begin{array}{l}\text { Aerosol formulation for rapid action applied by crew with passengers on } \\
\text { board, before take-off }\end{array}$
\end{tabular}

Top-of-descent

Aerosol formulation for rapid action applied by crew upon descent to arrival airport

Residual application

Concentrated formulation for residual action applied by trained operators in the absence of crew and passengers. Re-treatment advised at 8-week intervals

On-arrival

Acceptable back-up method in case of inadequate disinsection by any of the above methods.

In-flight aerosol treatment and residual treatment differ in the specific insecticides needed, and optimal time for carrying out treatment.

Pre-embarkation treatment is the most recent method of aircraft disinsection (DAFF/MPI, 2012), but is not yet a WHO-recommended practice. Undertaken prior to passenger boarding, it differs from residual treatment in that the applied insecticide lasts only for the duration of a single flight sector.

Source: WHO (1995)

millions of lives at risk (Phyo et al., 2012).

It has been documented that there has been a 30 -fold increase in dengue fever disease incidence over the last 50 years (CDC, 2014). The Centres for Disease Control and Prevention estimate that forty percent of the global population is at risk from the dengue virus, with Southeast Asia and Latin America being most affected. Tourism destinations in Asia are increasingly expressing concern about earning a reputation as dengue-infested destinations, posing a threat to tourism at large. For example, Sri Lanka recorded over 30,000 reported cases of suspected dengue fever in 2013 alone (UK Government, 2014). Importantly, the highest incidence of dengue cases was reported during January, coinciding with the peak winter tourism season. In the light of the growing threat of dengue worldwide, such numbers also make a strong case for tourism-dependent economies being adversely affected by dengue outbreaks.

Changing climates and human behaviour can also have important effects on disease dissemination. There is growing realisation that with rising traffic levels and regionally changing climates, these risks will vary, both seasonally and year-by-year. Compounding this problem is the human-induced loss of biodiversity worldwide. Variation in the diversity of suitable hosts may magnify the risk of human exposure to vector-borne diseases. Ostfeld and Keesing
(2000) point to the fact that human health is protected when many other hosts are present. This reduced risk of disease transmission is called the "dilution effect".

Aircraft disinsection procedures (see Table 2) were first published by the WHO in 1961 against the background of poor quarantine measures at some airports, and the then available scientific evidence on disease vectors (WHO, 1961).

\section{Towards a tourism-linked research agenda The problem}

Several factors can be identified as limiting the feasibility of the disinsection practices. They include the difficulty of compliance monitoring, the interruption to airline operations, the practicality of treating different aircraft compartments separately and passenger complaints of 'irritation'. For a full review of all the evidence building this summary see Grout (2013). These issues concerning disinsection feasibility represent a thematic summary of the points raised from ten databases; international airline sources, national authoritative bodies and international organisations, and produced results that reflect a broad spectrum of players involved (see Figure 1.) Health Sciences libraries such as OVID and PubMed produced the majority of the reviewed scientific papers. In the review of the literature, the difficulty of obtaining reliable and detailed data on 
disinsection effectiveness and behaviours became apparent. The findings of the review reflect the crises of policy, country regulations, and feasibility of practices that characterise stagnation in contemporary aircraft vectorcontrol.

Differences in practices and regulations reflect distinct viewpoints regarding what constitutes 'effective' control. At the same time, outbreaks of vector-borne diseases have indicated that epidemics can easily cross national borders. While personal protection may self-evidently be deemed a positive measure, disinsection as public policy requires some justification and expert input, and needs to take full account of all stakeholders.

In a global context, the control of vector-borne diseases necessitates public health interventions that may infringe on the health of individuals for the sake of bringing about significant benefit for the wider community. The implications of disinsection can therefore be both positive and negative. Since the question of what constitutes 'effective disinsection' cannot likely be answered in a straightforward manner, the balance of benefits and risks from treatments has to be worked out through multidisciplinary studies.

\section{A. Research in the context of policy}

The opening of new tourism destinations in receptive regions are among the specific factors that place tourists at increased contact with a previously unfamiliar disease, promote dissemination of mosquito vectors, and precipitate disease emergence. Global benchmark policy standards to protect the health of travellers are established by the International Health Regulations (IHR). Together with two WHO publications (WHO, 1985; WHO, 1995), these form the basis of current disinsection practices. The WHO holds an anchor status in recommending procedures for aircraft disinsection, with airline practices and national legislation resting largely upon the credibility of WHO data. Rather than having an overall airline policy, airlines abide by national regulations, and follow $\mathrm{WHO}$ recommendations on how to disinsect, and what products to use (IATA, 2012). It is the airlines' responsibility to ensure that insecticide products used meet aviation and aircraft manufacturer technical and safety requirements, as well as meeting country-specific requirements. Application practices vary by airline and destination, and are dependent on national regulations. The

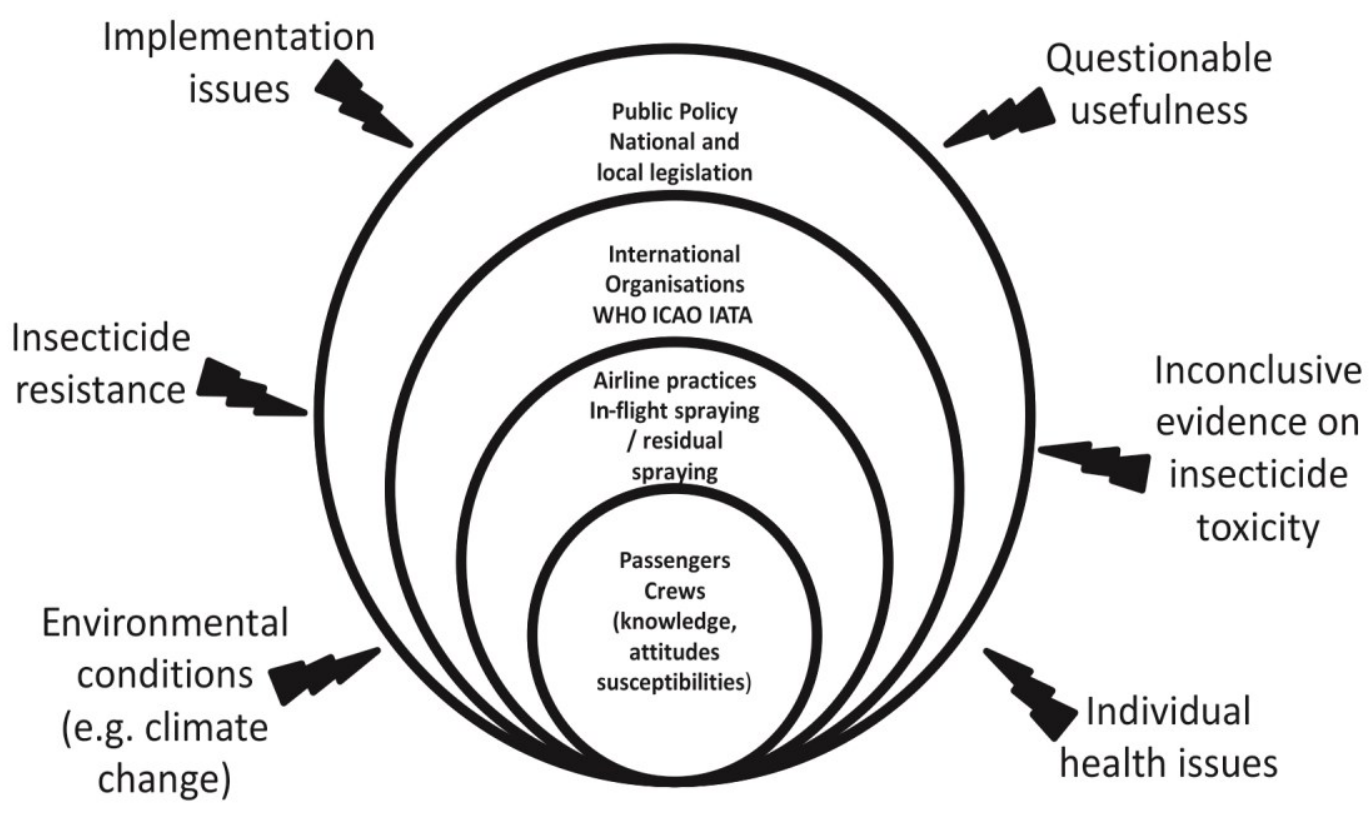

Figure 1. Limiting factors for disinsection control 
ICAO reported evidence of significant variability in vector control methods between airlines and contracting states (IACO, 2004), and noted the lack of both guidance material, and appropriate means to ensure compliance (ICAO, 2010).

Underlying the WHO recommendations is the premise that implementation of control measures must be complied with in order to be effective. However, the IHR provide no enforcement mechanism or penalty for noncompliance. For example, inadequate aerosol application may reduce effectiveness, and lead to failure to meet country requirements (Sullivan et al., 1972). This point is further reflected in the WHO's language being 'permissive' rather than mandatory. Enforcement of control measures may thus prove problematic.

Similarly, there is no jurisdiction beyond national borders. For example, U.S. national policy may be violated when residually treated aircraft, say from Australia-bound flights, also operate within the USA, as pyrethroid-based insecticides must not be used in U.S. passenger cabins at all (EPA, 2008). Consequently, U.S. airlines cannot legally apply pyrethroid insecticides to satisfy the requirements of countries that demand disinsection. In order to comply with both
Environmental Protection Agency (EPA) restrictions, and country requirements, U.S. airlines are forced to purchase disinsection products and treat aircraft in other countries (Delta Airlines, 2012). This represents a loophole in EPA regulations over which the agency may have little control. Of particular relevance is the fact that erratic scheduling would prohibit restricting residually treated aircraft to high-risk flights in order to prevent insecticide exposure to aircrews. Efforts to comply with disinsection requirements may thus provoke legal actions by exposing crews or passengers to insecticides that are prohibited for use within the United States. Similarly, threats of litigation also exist for exposing passengers and crew to potentially disease-carrying mosquitoes. Decisions to resume practices are thus difficult to make in the absence of reliable data.

The WHO recommends the use of surveillance information to limit disinsection requirements to high-risk flights (WHO, 2012b). It is interesting to note that some countries which insist on disinsection of all incoming aircraft, are often reservoirs of vector-borne diseases on outbound flights (e.g. India), and thus may be at greater risk of exporting vectors. This raises the question of whether disinsection is justified despite the low risk of vector importation from

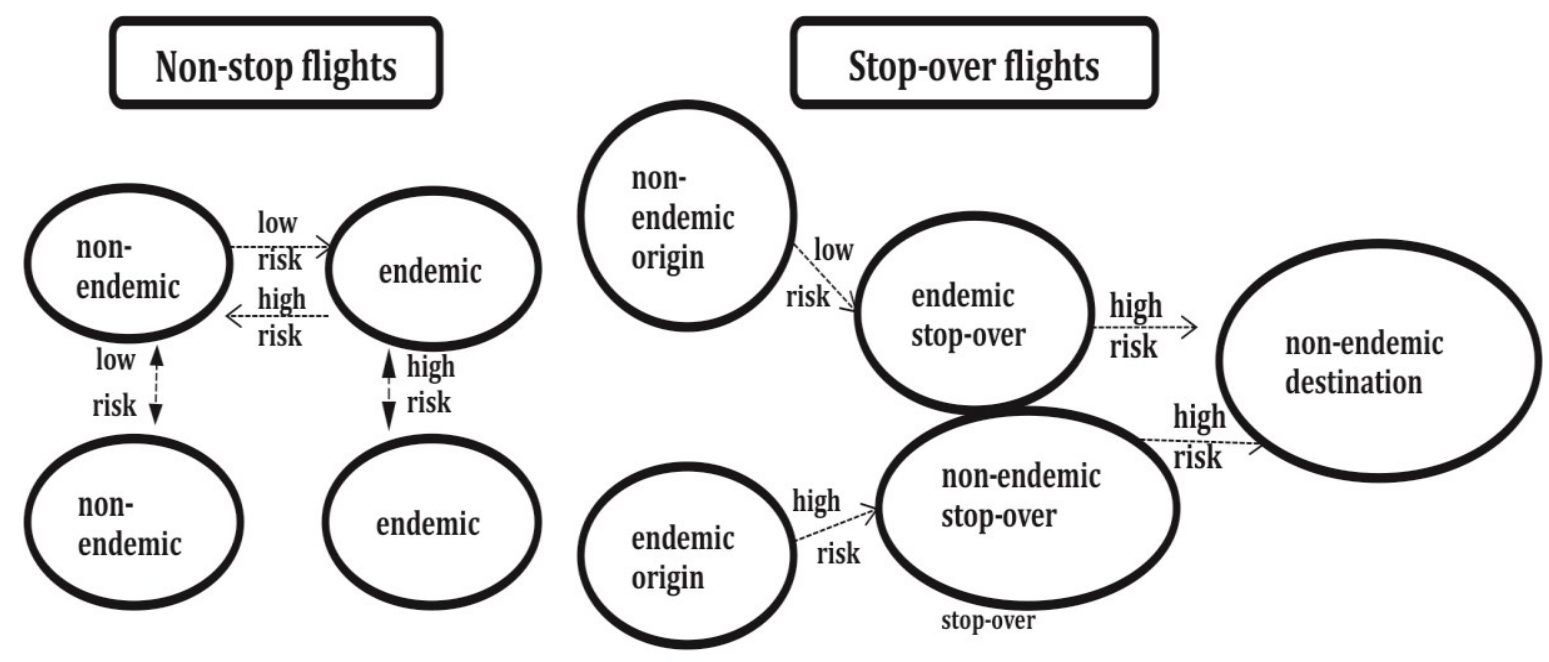

Figure 2. Risk for vector transmission on non-stop and stopover flights 
flights originating in vector-free regions. Research designed to more clearly establish the causal direction of relationships between tourism destinations and the risk of disease transmission is needed. It may be particularly interesting for future research to determine if national regulations go along with any tourismrelated legislation, and whether country strategies work towards the stimulation of international tourism.

The complexity of the policy control environment and the travel possibilities which need to be considered by researchers are identified in Figure 2.

The potential direct implications for tourism destinations must be noted here. In the absence of real time data, countries may well be at risk of local outbreaks despite being classified 'non-endemic'. For example, countries may lack the surveillance instrumental in confirming the endemic presence of dengue transmission, or diseasecarrying mosquito species may have unwittingly established, as is evident for Northern Italy (Rovida et al., 2011) and Southern France (Laruche et al., 2010).

\section{B. Passenger perception of disinsection and disease}

Russel and Paton (1989) proposed that rather than the technical effectiveness of insecticides, the acceptability of chemical treatment by passengers should be a guiding factor for standard disinsection procedures. Extending this approach it is possible to call for largescale airport surveys that explore this issue and assesses the educational needs for those traveling to risk destinations. Initiatives to improve such education should target all groups of travelers. In order to limit the potential importation of disease vectors and consequent implications for the tourism sector at large, travel health advice providers and airlines could expand their efforts to make travelers comply with the recommended travel health advice (Van Herck et al., 2006).

While the 2014 World Health Day aims at improving individual knowledge about vectorborne diseases, balancing the protection of individual health information with the need to protect public health remains a challenge.

Public health ethics dictate that public concerns about health risks and their perceptions need to be taken into account in decision-making (Bennett and Calman, 1999). Although the WHO recommends that passengers be informed of treatments, there are no defined requirements to do so and no timescales for a suitable time for notification. The IHR Annex 9 , Chapters 2.27 note:

'Contracting States shall, upon request, provide to aircraft operators appropriate information, in plain language, for air crew and passengers, explaining the pertinent national regulation, the reasons for the requirement, and the safety of properly performed aircraft disinsection'

Airlines are not required to inform passengers at ticket purchase of in-flight treatments, and there is no control over the amount of insecticide applied on aircraft. Airline policies thus may differ in that announcements are made shortly before spraying, or that formal announcement are not made at all, with instructions to merely respond to passenger queries (Allergy UK, 2012). As failure to disinsect could result in the aircraft being denied permission to land, passenger objections would constitute a considerable obstacle to flight operations. In addition, passengers are not likely to be given advance notification of any other types of disinsection, such as residual treatment. Accurate information about the discretionary spray practices of individual airlines may be difficult to obtain. However, even if travelers choose to avoid flying on routes where spraying is required, local rules may be implemented adhoc if deemed necessary. Similarly, failure to carry out disinsection may result in disembarkation being refused and remedial onarrival treatment being undertaken by local health authorities (Air Canada, 2011). Figure 3 and Figure 4 highlight these issues for further analysis. 
'To spray or not to spray': developing a tourism-linked research agenda for aircraft disinsection.

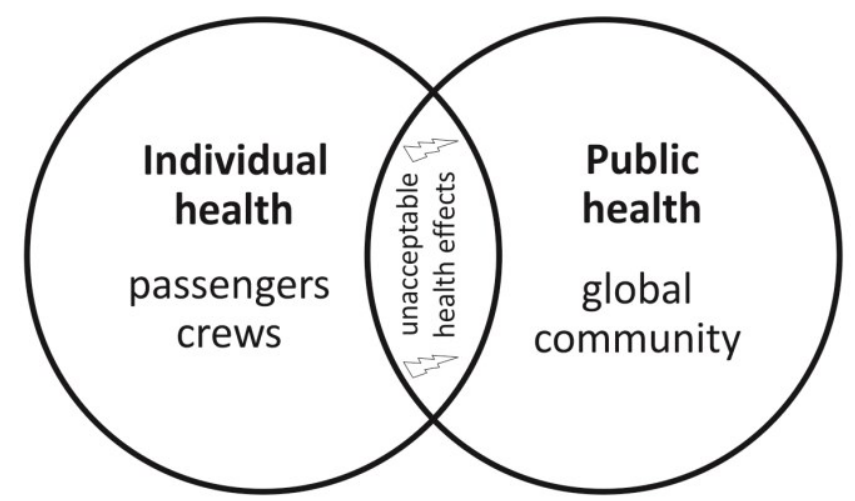

Figure 3. Points of friction for individual and public health interests

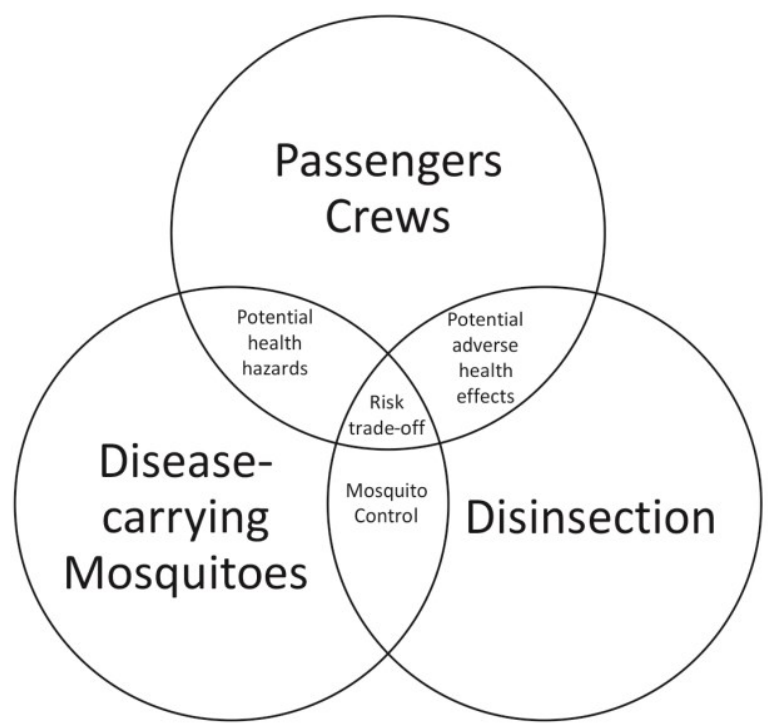

Figure 4. Risk trade-off for chemical disinsection

The following snippets of conversation from frequent traveler portals and social media platforms serve to illustrate some of the needs and challenges facing future disinsection research and practice:

"Airlines carry on a campaign of silence and misinformation about the potential effects on passengers of cabin spraying" "We have no choice but to breathe in poisons"

"Sometimes they spray, sometimes not"
"Do they regularly fumigate coach but not business/first class?"

"I was subjected to this spraying and I find it deplorable, and feel worse for the flight attendants, who have to breathe this stuff on a regular basis"

"Administration of the insecticide was against our will, without our explicit permission, and thus in clear violation of medical ethics and generally accepted international norms of medical care"

These themes are summarised in Table 3. 
Table 3. Key passenger concerns, needs and conflicts about disinsection.

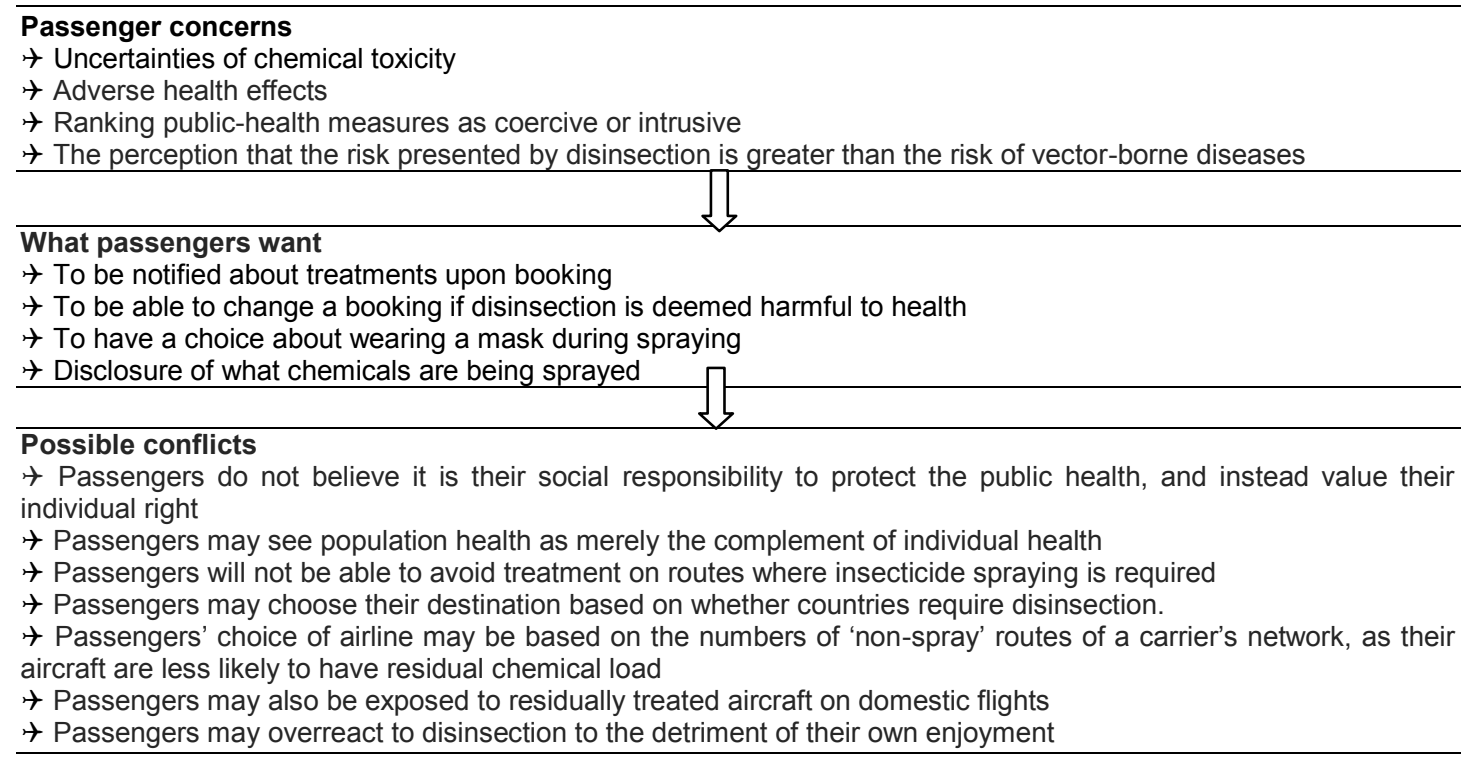

Tourists and travellers are at the front line of exposure to vector-borne diseases. Knowledge of the factors underlying passenger concerns can help focus resources on the key situations and global tourism areas, and develop more effective prevention strategies. The opportunity to research these issues and provide a more solid foundation to discuss passenger concerns is a pivotal tourism research direction. The existing lack of conclusive evidence establishing a direct link between disinsection and other medical conditions may largely contribute to a climate of uncertainty and suspicion. The improved management of risk perception for passengers is likely to enhance overall acceptance of procedures.

\section{Aircrew perspectives and behaviours}

The debate over chemical safety of disinsectants has grown largely as a result of anecdotal reports by passengers and crews. Although no strong scientific evidence exists to support these claims, subjective observations and assessments of the effects of some chemicals on health have been obtained from flight reports and passenger comments. Reports of symptoms allegedly caused by exposure to insecticides may have generated increased hostility towards chemical disinsection. This point has been repeatedly emphasised by Murawski (2005), who notes that evidence on repeated exposure to insecticides and potentially cumulative health effects in particular is lacking. The risks of adverse health effects from disinsection are particularly significant for aircrew, who may be subjected to multiple exposures during short periods of time (Hocking, 2002). According to Murawski, the ICAO Facilitation Panel has repeatedly proposed that limits to routine inflight spraying should be made mandatory. However, there remains no meaningful enforcement mechanism to ensure that contracting states comply with these ICAO requirements.

Non-compliance by crews to carry out disinsection is likely to be an important factor leading to unsuccessful outcomes. This is possibly attributable to uncertainties in toxicity, leading to increasing aversion towards insecticides.

Most studies point to a worldwide lack of compliance, and conclude that uncertainty of toxicity and adverse health effects of chemical disinsection are believed to contribute to noncompliance (Smith and Carter, 1984; Guillet et al., 1998; Berger-Preiss et al., 2004, 2005). The disadvantages of in-flight spraying are clear in that cabin crews need to be trained and monitored for compliance. Several authors 
'To spray or not to spray': developing a tourism-linked research agenda for aircraft disinsection.

have highlighted the complexity of the situation; a wide range of efficacy is created by the application of incomplete dosages, inadequate coverage, and total non-performance (Dale, 1982; Smith and Carter, 1984; Gratz et al., 2000). Inconsistent application may further reduce confidence in vector control, thus spurring non-compliance.

Additionally, a lack of awareness of the possible consequences of vector-borne diseases, or advice given by local medical practitioners that may contradict the advice given by occupational health departments, are further possibilities for resentments towards treatments. In either case, the underlying rationale for non-compliance hampers the overall success of control measures.

Educating aircrews about vector-borne diseases is essential. Compliance with treatment protocols is likely to be much greater when the serious nature of the diseases and the effectiveness of disinsection are understood. More senior staff may have established beliefs and practices which, if inappropriate, need to be tactfully challenged. Information must entail clear instructions on use that should be complied with and followed precisely.

Even small modifications in the application of insecticides may have critical ramifications on either the chemical effectiveness or human health. This generates new and exciting challenges in understanding aircrew behaviour with regard to health-related duty protocols. Crew members are generally a heterogeneous population, and they may have very different valuations of the potential health risks. Questions as to how air travel disrupts aircrew behaviour and how social and normative considerations affect the way aircrew interact with one another and with passengers remain largely unknown and understudied.

\section{$D$. Interpretation and education}

There is inadequate information to determine that aircraft disinsection as currently practiced is safe for passengers and aircrews (Murawski, 2005). To date, information regarding acceptance of disinsection treatments from the passengers' and crew members' perspectives are lacking a sound scientific evidence base. Similarly, airline management may not have a clear understanding regarding the requirements of vector-borne disease control. This is particularly relevant as aircrew workers are more likely to subscribe to requirements which are fully endorsed by management. Assessing information adequacy and establishing a benchmark for health risk perception requires consideration of the appropriateness of disinsection per se, and the context of recent trends in media coverage over potential cabin contaminants (Bagshaw, 2013), which may have further spurred the resentment towards chemical treatments. Passengers and aircrews are likely to have different ideas of appropriateness and adequacy of treatments. In the absence of scientifically sound knowledge base as a benchmark knowing whether available information on disinsection is adequate or acceptable on the basis of anecdotal opinion can be difficult.

The assessment of information needs is important here; that is, what information is provided (e.g. by airlines, medical professionals or internet services), and how far information needs are being met. Decisions will then need to be made over what methods for disseminating information would best suit passengers and aircrews respectively. The research question to be addressed here is to what extent the assumptions about crew and passenger behaviour in the policy and control protocols hold in practice?

\section{E. Medical effectiveness}

It is generally acknowledged that disinsection operations provide a first-line defense to prevent the introduction of mosquito vectors. While the efficacy of specific chemical agents has been evaluated extensively in laboratory and field trials, tests have shown that the degree of effectiveness varies with the type of insecticide used, the type of insect targeted, and the feasibility of a particular method relating to the aircraft environment (Sullivan et al., 1972; Russel and Paton, 1989; BergerPreiß et al., 2004, 2005). Procedures that work in trials under controlled and optimal conditions may thus have poor implementation results, and grossly oversimplify the mechanisms of effective control measures. For any control 
method, a gap may thus exist between efficacy in theory, and effectiveness under operational conditions. More importantly, the relative effectiveness of aircraft disinsection in preventing vector-borne diseases is not welldescribed in the literature (Murawski, 2005).

The role of pyrethroid insecticides in aircraft disinsection necessitates a thorough understanding of the environmental fate and ecological effects of their use. Insecticides may have significantly changed the equation for effective outcomes of mosquito control efforts. As the number of genetically resistant species evolving increases, the use of alternative insecticides should be weighed carefully, and considered only once conclusive scientific proof of resistance has been obtained. Singh et al. (2010) further stress the importance to correctly identify mosquito species before implementing control programs. Misidentification may have important consequences on mosquito resistance to specific insecticides, thus hamper both effectiveness and efficiency of procedures. In addition, Hocking (2002) notes how current control procedures are inadequate to control certain mosquito populations. The type and frequency of mosquito importation must be established before it can be determined whether, and to what extent, disinsection meets the desired effects.

Guillet et al. (1998) stressed the importance of focusing control regimes on high-risk flights, and concludes that failure of research to take into consideration stopovers, charter, military, cargo, and private flights is a major factor that hampers effective control and risk assessments.

Advancements into mechanical means of vector control triggered an approach towards the ultimate goal of adaptive disease management that largely relied on forecast data to limit the use of chemical disinsection. For example, Huang et al. (2012) describe the development of a Web-based GIS tool to better forecast the risks of vector-borne disease by air travel. Such tools could better inform tourism operators of the specific vectors circulating in different regions, and also enable airlines to limit chemical disinsection by targeting high-risk flights. Designed for a wide range of users beyond the airline and government stakeholders (Huang et al., 2012), such approaches could also inform decision makers and health planners from other tourism sectors on the risk factors behind vector-borne disease importation and onward spread risk.

The effectiveness of disinsection procedures will be critical to vector management. While research into air curtains has been put back on the agenda at the 2013 Aviation Conference London (WHO, 2013) it will be necessary to reinvigorate efforts to include mechanical methods as standard procedure for aircraft disinsection. In order to establish an evidencebase, future research should continue collection of scientific data that compares the efficacy of chemical disinsection with nonchemical methods; expand the scope of disinsection studies to incorporate all types of feasibility issues with the potential to impact on the effectiveness of measures; and address the mitigation of social and economic and effects.

\section{Conclusion}

The title of this review asks the question which approach is justified - to spray or not to spray. Vector importation and establishment have farreaching consequences that go beyond individual health and touch on the well-being of societies. As the control of vector-borne diseases requires public health interventions that often infringe on the rights of individuals, individual exposure risks of insecticides will be difficult to resolve in light of the primary functions of aircraft disinsection as a public health measure for the common good (Hocking, 2002). It is important to recognise the larger issue at hand. The debate regarding disinsection reflects the underlying conflict of individual rights versus the public good.

One area of particular concern is how climate change will affect the spread of mosquito-borne diseases. By contrasting the likely increase in global temperature over the next 100 years with the relatively small fluctuations that influenced the outbreak and spread of the bubonic plague in mid-14th century Europe, McMichael (2012) alerts all stakeholders to the unprecedented risks to human health, and warns that climate change may weaken the 
very foundations of human life support systems.

Due to the broad focus of past scientific analysis, most studies have not examined closely the underlying constraints for aircraft disinsection. However, by combining the state of medical knowledge with the tourism and social science areas identified in this review, new research approaches to disinsection can be attempted. These studies should hopefully help prompt action in new directions, rather than formalising and repeating current unsound practice. To avoid an unbalanced account of disinsection practices, further research must address both the benefits and risks of disinsecting, and not disinsecting aircraft.

Aircraft disinsection is an example of a situation in which taking action to reduce one health risk may create another. The challenge for public health and tourism studies is to determine the nature and degree of appropriate intervention, and to weigh significant trade-offs in deciding how to act: the risk for vector-borne diseases against the risk of human exposure to pesticides used to control mosquitoes. After nearly a decade of debate, the facts on unprecedented changes in volume and extend of air travel, as well as environmental factors that this review addressed, may help invigorate the disinsection revision process. The multiple stakeholders involved in the future management of the problem are represented in Figure 5.

\section{Areas for research}

The core directions for a research agenda focussing on disinsection which can be identified from this review serve as a concluding list for tourism researchers and their colleagues.

$>$ Define and explore the key philosophical issues about rights relevant to the optimal delivery of disinsection treatments for communities, passengers and aircrews

$>$ Investigate to what extend public policy incorporates tourism with respect to reducing health risks and uncertainties

$>$ Build a coherent thread of airline studies,

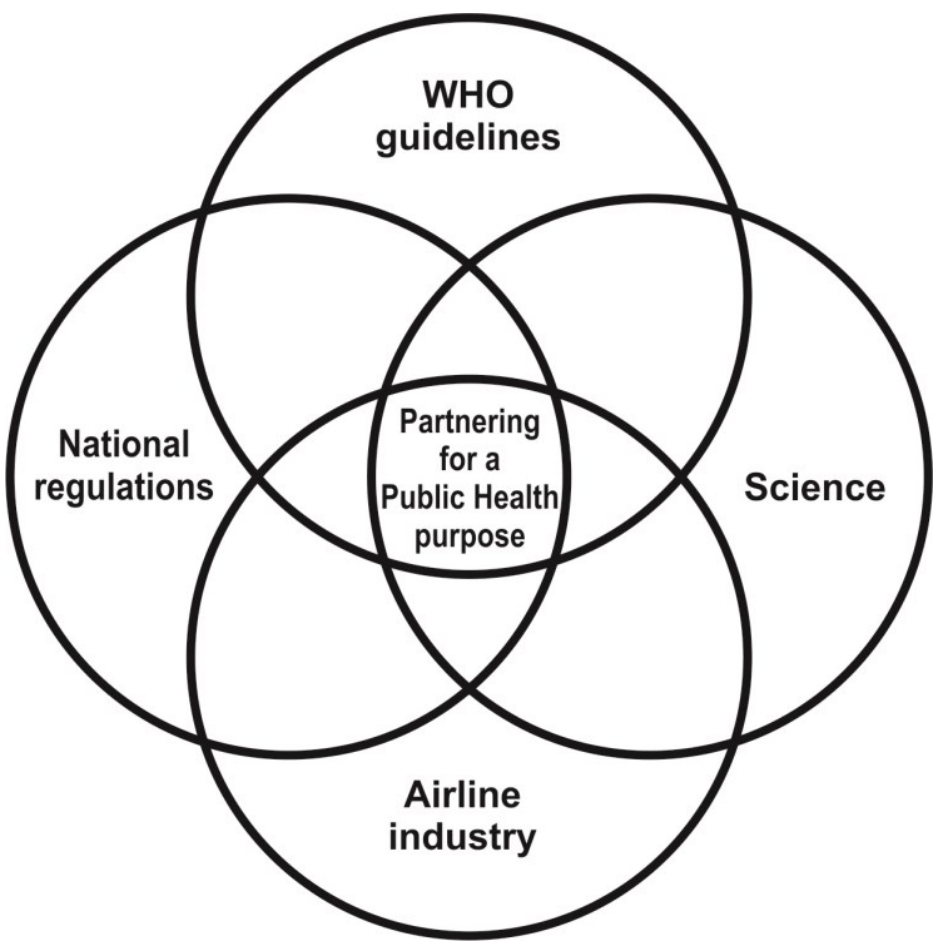

Figure 5. Partnering for a global health purpose 
thus placing health related studies in a broader tourism research context

> Assess how public health policy influences travel behaviour, and how tourist behaviour related to health issues is regulated in different countries

$>$ Document the ways the tourism sector can adapt to the changes in disease transmission. Is there a global tourism response framework?

$>$ Strengthen collaboration at national and local levels between tourism and health researchers for joint study efforts

$>$ Research the relationship between aircrew lifestyle, values and health concerns and compliance behaviour

$>$ Conduct a risk perception survey with broad international reach to explore passengers' and aircrew attitudes towards disinsection.

Taken individually or more desirably in concert, the findings from fulfilling this research agenda could shape the future of spraying on aircraft, and beyond that goal contribute to the welfare of people in many destinations.

\section{Note}

In accordance with recent taxonomic decisions, the genera Aedes have been renamed Stegomyia. Throughout this paper the name Aedes is employed for matters of consistency with research findings.

\section{References}

Air Canada (2012). Health tips. URL: http://www.aircanada.com/en/travelinfo/onb oard/healthtips.html (Accessed on 10.06.2012)

Allergy UK (2012). Travelling by air with MCS Disinfectant Spraying Aboard Aircraft.

URL:http://www.allergyuk.org/downloads/factsh eets/intolerances-andsentivities/Travelling\%20by\% 20air\%20with\%20MCS.pdf (Accessed on 22.06.2014)

Bagshaw, M. (2013). Health Effects of Contaminants in Aircraft Cabin Air.

URL:http://www.gapan.org/file/1072/healtheffects-of-contaminants-in-aircraft-cabinair-summary-report-v2.3.pdf (Accessed on 15.08.2013)
Bennett, P. and Calman, K.C. (ed.) (1999). Risk, communication and the public health. Oxford: Oxford University Press.

Berger-Preiß, E., Koch, W., Behnke, W., Gerling, S., Kock, H., Elflein, L. and Appel, K.E. (2004). In-flight spraying in aircrafts: determination of the exposure scenario. International Journal of Hygiene and Environmental Health, 207(5), 419-430.

Berger-Preiß, E., Koch, W., Gerling, S., Kock, H., Klasen, J., Hoffmann, G. and Appel, K.E. (2006). Aircraft disinsection: Exposure assessment and evaluation of a new preembarkation method. International Journal of Hygiene and Environmental Health, 209(1), 41-56.

CDC Centers for Disease Control and Prevention (2014). National Center for Emerging, Zoonotic, and Infectious Diseases, Division of Vector-Borne Diseases. Atlanta, USA.

Conlon, C.P., Berendt, A.K., Dawson, K. and Peto, T.E.A. (1990). Runway malaria. The Lancet, 335, 472-473.

Crompton, J. (1979). Motivations for pleasure vacation. Annals of Tourism Research, 6(1), 408-442.

Crompton, J. and Ankomah P.K. (1993). Choice set propositions in destination decisions. Annals of Tourism Research, 20, 461-476.

Cummings, D.A., Irizarry, R.A., Huang, N.E., Endy, T.P., Nisalak, A., Ungschusak, K. and Burke D.S. (2004). Traveling waves in the occurrence of dengue haemorrhagic fever in Thailand. Nature, 427 (6972), 344347.

DAFF/MPI Department of Agriculture, Fisheries and Forestry Australia (2014). Schedule of Aircraft Disinsection Procedures for Flights into Australia and New Zealand. Version 3.2. Last reviewed: March 2014. URL: http://www.daff.gov.au/_data/assets/pdf_fi le/0005/111992/aircraft-disinsectionv3.2.pdf (Accessed on 12.06.2014)

Dale, P.S. (1982). Effectiveness of permethrin residues against insects carried in aircraft. New Zealand Entomologist, 7(3), 310-313.

Delta Airlines (2012). Steve Tochlin, Environmental Health Manager, Information received in writing on 02.04.2012 
'To spray or not to spray': developing a tourism-linked research agenda for aircraft disinsection.

EPA Environmental Protection Agency USA (2008). Re-registration Eligibility Decision for d-phenothrin URL: http://www.epa.gov loppsrrd1/REDs/sumithrin_(d-henothrin) _red.pdf (Accessed on 15.10.2011)

Giacomini, T., Mouchet, J., Mathieu, P. and Petithory, J.C. (1994). Study of 6 cases of malaria acquired near Roissy-Charles-deGaulle in 1994. Necessary prevention measures in airports. Bulletin de l'Academie Nationale de Medecine, 9, 350351.

Gratz, N.G., Steffen, R. and Cocksedge, W. (2000). Why aircraft disinsection? Bulletin of the World Health Organisation, 78, 9951004.

Grout, A. (2013). International air traffic and vector-borne diseases: The role of airlines in containing import and spread of mosquito vectors. Master of Public Health thesis. University of London, (Unpublished dissertation).

Gubler D. (2008). The global threat of emergent/ reemergent vector-borne diseases. In: Vector-Borne Diseases: Understanding the environmental, human health, and ecological connections. Washington, DC: Institute of Medicine, The National Academies Press, 43-46.

Guillet, P., Germain, M.C., Giacomini, T., Chandre, F., Akogbeto, M., Faye, O., Kone, A., Manga, L. and Mouchet, J. (1998). Origin and prevention of airport malaria in France. Tropical Medicine and International Health, 3(9), 700-705.

Hocking, M.B. (2002). Trends in Cabin Air Quality of Commercial Aircraft: Industry and Passenger Perspectives. Reviews on Environmental Health, 17(1), 1-49

Huang, Z., Das, A., Youliang, Q. and Tatem A.J. (2012). Web-based GIS: the vectorborne disease airline importation risk (VBDAIR) tool. International Journal of Health Geographics, 11(1), 33.

IATA International Air Transport Association (2012).

URL:http://www.iata.org/about/Pages/missi on. aspx (Accessed on 05.12.2012).

ICAO International Civil Aviation Organisation (2004). Report on activities of the FAL programme.

URL:http://legacy.icao.int/icao/en/atb/meeti ngs/2004/fal12/documentation/fal12ip005 en.pdf (Accessed on 10.07.2012)

ICAO International Civil Aviation Organisation (2010). Preventing the spread of communicable disease through nonchemical methods. A37-WP/59, Agenda Item 43. Paper presented at the 37th Session of the ICAO Assembly, Aviation data, Technical Commission on $14^{\text {th }}$ July 2010, Montreal, Canada

Isaäcson, M. (1989). Airport malaria: a review. Bulletin of the World Health Organization, 67, 737-743.

Iso-Ahola, S.E. (1982). Toward a social psychological theory of tourism motivation: A rejoinder. Annals of Tourism Research, 9(2), 256-262.

Kahneman, D. (2012). Thinking, Fast and Slow. London: Allen Lane

Kim, S. S., Guo, Y. and Agrusa, J. (2005). Preference and positioning analyses of overseas destinations by Mainland Chinese outbound pleasure tourists. Journal of Travel Research, 44(2), 212-220.

Krippendorf, J. (1987). The Holiday Makers: Understanding the Impact of Leisure and Travel. London: London: William Heinemann.

Lai, C., Li, X. and Harrill, R. (2013). Chinese outbound tourists' perceived constraints to visiting the United States. Tourism Management, 37, 136-146.

Laruche G., Souarès, Y., Armengaud, A., Peloux-Petiot, F., Delaunay, P., Desprès, P., Lenglet, A., Jourdain, F., LeparcGoffart, I., Charlet, F., Ollier, L., Mantey, K., Mollet, T., Fournier, J.P., Torrents, R., Leitmeyer, K., Hilairet, P., Zeller, H., van Bortel, W., Dejour-Salamanca, D., Grandadam, M. and Gastellu-Etchegorry M. (2010). First two autochthonous dengue virus infections in metropolitan France, September 2010. Euro Surveillance, 15(39).

Lines, J. (2007). Chikungunya in Italy: globalisation is to blame, not climate change. British Medical Journal, 335.

McIntosh, I., Swanson, V., Power, K., Raeside, F. and Dempster, C. (1998). Anxiety and health problems related to air travel. Journal of Travel Medicine, 5(4), 198-204.

McMichael, A.J. (2012). Insights from past millennia into climatic impacts on human 
health and survival. Proceedings of the National Academy of Sciences of the U.S.A. 109, 4730-4737.

Murawski, J. (2005). Insecticide use in occupied areas of aircraft. In Hocking, M. (ed.): Air Quality in Aircraft Cabins and Similar Enclosed Spaces (2005) pp 169190. Springer: Berlin/Heidelberg. Additional information received in writing on 15 Aug 2012.

Ostfeld, R.S. and Keesing, F. (2000). Biodiversity and disease risk: the case of Lyme disease. Conservation Biology, 14, 722-728.

Page, S. J. (2009). Transport and Tourism. Global perspectives. 3rd edn. Harlow: Pearson

Page, S. and Connell J. (2014). Transport and Tourism. In: Lew, A., C. M. Hall, A. Williams (ed.) (2014) The Wiley Blackwell Companion to Tourism. Oxford: Wiley Blackwell, 155-167.

Pearce, P.L. (1988). The Ulysses Factor: Evaluating visitors in tourist settings. New York: Springer-Verlag

Phyo, A.P., Nkhoma, S., Stepniewska, K., Ashley, E.A., Nair, S., McGready, R., Moo, C., Al-Saai, S., Dondorp, A.M., Lwin, K.M., Singhasivanon, P., Day, N.P.J., White, N.J., Anderson, T.J.C. and Nosten, F. (2012). Emergence of artemisinin-resistant malaria on the western border of Thailand: a longitudinal study. The Lancet, 379(9830), 1960-1966.

Plog, S. (1987). Understanding psychographics in tourism research. In Ritchie, J.R.B., C. Goeldner (ed.) (1987) Travel Tourism and Hospitality Research. New York: Wiley, 203-214.

Plog, S.C. (1974). Why Destinations Rise and Fall in Popularity. Cornell Hotel and Restaurant Quarterly, 14(4), 55-58.

Rizzo, F., Morandi, N., Riccio, G., Ghiazza, G. and Garavelli P. (1989). Unusual transmission of falciparum malaria in Italy. The Lancet, 333, 555-556.

Rovida, F., Percivalle, E., Campannini, G., Piralla, A., Novati, S., Muscatello, A. and Baldanti, F. (2011). Viremic dengue virus infections in travellers: potential for local outbreak in Northern Italy. Journal of Clinical Virology, 50(1), 76-79.
Russell, R.C. and Paton, R. (1989). Inflight disinsection as an efficacious procedure for preventing international transport of insects of public health importance. WHO Bulletin, 67(5), 543-547.

Singh, O.P., Nanda, N., Dev, V., Bali, P., Sohail, M., Mehrunnisa, A., Adak, T. and Dash A.P. (2010). Molecular evidence of misidentification of Anopheles minimus as Anopheles fluviatilis in Assam (India). Acta Tropica, 113(3), 241-244.

Smith, A., Carter, I.D. and Laird, M. (1984). International transportation of mosquitoes of public health importance. In: Laird M (ed) (1984) Commerce and the spread of pests and disease vectors. New York: Praeger, $1-21$.

Sullivan, W.N., Pal, R., Wright, J.W., Azurin, J.C., Okamato, R., McGuire, J.U. and Waters, R.M. (1972). Worldwide studies on aircraft disinsection at "blocks away". Bulletin of the World Health Organisation, 46(4), 485-491.

Tatem, A.J., Rogers, D.J. and Hay S.I. (2006). Global traffic and disease vector dispersal. Proceedings of the National Academy of Sciences of the U.S.A. 103, 6242-6247.

UK Government (2014) Foreign Travel Advice. Sri Lanka. URL: https://www.gov.uk/foreign-traveladvice/sri-lanka/health (Accessed on 10.06.2014)

Van Herck, K., Castelli, F., Zuckerman, J., Nothdurft, H., Van Damme, P., Dahlgren, A.-L., Gargalianos, P., Lopéz-Vélez, R., Overbosch, D., Caumes, E., Walker, E., Gisler, S. and Steffen, R. (2006). Knowledge, Attitudes and Practices in Travel-related Infectious Diseases: The European Airport Survey. Journal of Travel Medicine, 11(1), 3-8.

WHO World Health Organisation (1961). Aircraft Disinsection. $11^{\text {th }}$ Report of the Expert Committee on Insecticides, Geneva.

WHO World Health Organization (1963). Terminology of malaria and of malaria eradication: report of a drafting committee, 1-124, Geneva

WHO World Health Organization (1985). Weekly Epidemiological Record. Recommendations on the Disinsecting of Aircraft, 60, 45- 52. Paper presented on $15^{\text {th }}$ February 1985, Geneva 
WHO World Health Organization (1995). Report of the informal consultation on aircraft disinsection, International Programme on Chemical Safety (IPCS), WHO/IPCS/95.51, 195, Geneva.

WHO World Health Organisation (2003) Climate change and human health: Risks and responses. In: McMichael, A.J., Campbell-Lendrum, D.H., Corvalan, C.F., Ebi, K.L., Githeko, A., Scheraga, J.D. and Woodward A. (ed) (2003) Vector-Borne Diseases: Understanding the Environmental, Human Health, and Ecological Connections. Workshop Summary (Forum on Microbial Threats). Geneva: National Research Council, 8-12.

WHO World Health Organization (2004). Disinsection and Pesticides in Aircraft Cabins. Paper presented at the $12^{\text {th }}$ session of the Facilitation Division in Cairo on $22^{\text {nd }}$ March- $2^{\text {nd }}$ April 2004
WHO World Health Organitzation (2005). Atlas of insecticide resistance in malaria vectors of the WHO African region, African Network for Vector Resistance.

WHO World Health Organization (2012a). Malaria Report 2012. URL: http://www.who.int/malaria/publications/wor Id_malaria_report_2012/en/ (Accessed on $0 \overline{9} .06 .201 \overline{4})$

WHO World Health Organization (2012b). Aviation Health Conference, $2^{\text {nd }}-3^{\text {rd }}$ October 2012, London

WHO World Health Organization (2013). Aviation Health Conference, $24^{\text {th }}-25^{\text {th }}$ September 2013, London

WHO World Health Organization (2014). WHO Campaigns, World Health Day 2014: Vector-borne diseases, Geneva 